University of Nebraska - Lincoln

DigitalCommons@University of Nebraska - Lincoln

7-2011

\title{
Importance of Characterizing Nanoparticles before Conducting Toxicity Tests
}

\author{
Yi Cong \\ Roskilde University, Roskilde, Denmark, cong@ruc.dk \\ Chengfang Pang \\ Roskilde University, Roskilde, Denmark, pang@ruc.dk \\ Lina Dai \\ Roskilde University, Roskilde, Denmark \\ Gary T. Banta \\ Roskilde University, Roskilde, Denmark \\ Henriette Selck \\ Roskilde University, hse@virgil.ruc.dk
}

See next page for additional authors

Follow this and additional works at: https://digitalcommons.unl.edu/biosciforbes

Part of the Pharmacology, Toxicology and Environmental Health Commons

Cong, Yi; Pang, Chengfang; Dai, Lina; Banta, Gary T.; Selck, Henriette; and Forbes, Valery E., "Importance of Characterizing Nanoparticles before Conducting Toxicity Tests" (2011). Valery Forbes Publications. 38. https://digitalcommons.unl.edu/biosciforbes/38

This Article is brought to you for free and open access by the Papers in the Biological Sciences at DigitalCommons@University of Nebraska - Lincoln. It has been accepted for inclusion in Valery Forbes Publications by an authorized administrator of DigitalCommons@University of Nebraska - Lincoln. 


\section{Authors}

Yi Cong, Chengfang Pang, Lina Dai, Gary T. Banta, Henriette Selck, and Valery E. Forbes 


\title{
Importance of Characterizing Nanoparticles before Conducting Toxicity Tests
}

\author{
Yi Cong,' Chengfang Pang,' Lina Dai,' Gary T Banta,' \\ Henriette Selck,' and Valery E Forbes I,2 \\ I. Roskilde University, Roskilde, Denmark \\ 2. University of Nebraska-Lincoln, Lincoln, Nebraska, USA \\ Corresponding author — Y. Cong, cong@ruc.dk
}

Rapidly expanding growth in the field of nanotechnology has led to the development of numerous applications of nanomaterials in industrial (e.g., paints, electronics) and consumer (e.g., cosmetics, clothing treatments) products. These engineered nanoparticle (NP)-containing products have, however, the potential to release particles (single or aggregates) or ions by means of wastewater discharge into the aquatic environment. SCENIHR (2006) emphasized that the behavior of NPs is critically dependent on several particle characteristics, including size, surface area and surface reactivity, and that risk assessments for both human health and the environment have to be based on these characteristics. However, in practice, risks of NPs are in most cases assessed on the basis of their chemical composition alone and, to date, no widely accepted or well-defined risk assessment methods or test strategies exist explicitly designed for NPs.

There is a growing consensus on the necessity of proper and accurate characterization of NPs in environmental media and biological systems to ensure reliable and reproducible toxicity tests are performed. Without such characterization, nanotoxicity experiments will have limited value due to unknown variability in experimental conditions of the NPs (Warheit 2008). Some of the current divergent or conflicting results from nanotoxicological tests could also be better explained if there had been adequate characterization in all studies. However, exhaustive characterization of NPs is undoubtedly costly and time-consuming, and therefore, a sufficient but practical approach is needed. Some principal characteristics of NPs which have been considered to deserve quantification before conducting toxicity tests are size, shape, state of dispersion, physical and chemical properties (e.g., electronic and optical properties, chemical composition and reactivity), surface area, and surface chemistry (Powers et al. 2006). Whereas a significant number of papers list some of these characteristics for the powder or the initial dispersion media (usually in distilled water) few, if any, studies of aquatic nanotoxicity have provided a full characterization of the size distribution (especially hydrodynamic size), dispersion state (especially in biological media) or surface chemistry (like surface charge) of NPs in the actual test media. However, many NPs are likely to undergo significant size distribution or surface chemistry changes when they are transferred between media during experiments, such as from dispersion media (deionized water) to test media (e.g., sediment, freshwater, seawater, and cell culture media). Such changes may alter bioavailability or toxicity in ways that are not entirely understood.

We have characterized commercially available Ag NPs before conducting toxicity tests (Cong et al. unpublished data) and found a clear difference between the manufacturer's information ( $<100 \mathrm{~nm}$ and 2 to $3.5 \mathrm{~mm}$, respectively) and what we measured ( 20 to $200 \mathrm{~nm}$ and $8 \mathrm{~nm}$ to $3 \mathrm{~mm}$ in deionized water, respectively) for $2 \mathrm{Ag}$ forms. This difference in size between that reported by the manufacturer and that measured in the laboratory was also observed by Scown et al. (2010). The reasons are most likely due to batch-to-batch variation during production, changes in material properties between synthesis and initial characterization, and particular experimental conditions when used (e.g., pH, ionic strength, and temperature). This observed variability highlights the importance of fully characterizing commercially obtained NPs before performing toxicity experiments, at the very least in the stock solutions used to prepare exposure treatments Given this sensitivity to experimental conditions, it is also important to characterize the NPs for each experiment conducted. 
The preparation of stock NP suspensions for characterization before conducting laboratory experiments usually uses external mixing forces, like solvent dispersion, shaking, centrifugation, ultrafiltration, sonication, as well as surface modification and coatings to make NPs disperse evenly. All of these processes and treatments may change the properties of the NPs and may, therefore, be environmentally unrealistic compared with NPs released to the environment. Environmental factors, such as water $\mathrm{pH}$, salinity and temperature, dissolved organic material, and natural competing cations, are likely to play important roles in determining the dispersion, toxic consequences, and compartment in which NPs are retained in the environment. Ideally, characterization of NPs should be performed under conditions as close as possible to the relevant exposure medium. For NPs intentionally or accidentally introduced into the aquatic environment, sediment is likely to act as a potential sink as it does for many chemicals. However, we know little about the state of sediment-associated NPs due to the limitation of techniques and methods for characterizing NPs in such complex and "dirty" media. We can start our exposures with nicely dispersed and well characterized NPs in a deionized water stock solution, but as soon as we add the solution to sediment we are working literally with a black box. Although we might expect NPs to become highly aggregated upon contact with sediment and therefore lose their tendency to behave differently than their chemically identical counterparts, our preliminary results suggest that this is not necessarily the case. Because the reactivity and toxicity of
NPs are believed to be influenced by such features as their size, shape, surface coating, and other properties, we conclude that both the physical and chemical properties of NPs must be systematically and adequately defined before toxicological studies and risk assessment. The publication of toxicity test results should require that a characterization be performed in stock solutions used for testing. At the same time, there is a pressing need for the development of better methods for effectively characterizing NPs in complex environmental media (e.g., seawater, sediment) and living tissue.

\section{REFERENCES}

Powers KW, Brown SC, Krishna VB, Wasdo SC, Moudgil BM, Roberts SM. 2006. Research strategies for safety evaluation of nanomaterials. Part Vl. Characterization of nanoscale particles for toxicological evaluation. Toxicol Sci 90:296-303.

[SCENIHR] Scientific Committee on Emerging and Newly Identified Health Risks. 2006. Opinion on the appropriateness of existing methodologies to assess the potential risks associated with engineered and adventitious products of nanotechnologies. Brussels, Belgium: SCENIHR 002/05.

Scown TM, Santos E, Johnston BD, Gaiser B, Baalousha M, Mitov S, Lead JR, Stone V, Fernandes T, JepsonM, Aerle VR, Tyler CR. 2010. Effects of aqueous exposure to silver nanoparticles of different sizes in rainbow trout. Toxicol Sci 1 15:521- 534.

Warheit DB. 2008. How meaningful are the results of nanotoxicity studies in the absence of adequate material characterization? Toxicol Sci 101:183- 185 . 